\title{
Study on the Characteristics of Information Service Industry in Yangtze River Delta
}

\author{
Shaoli $\mathrm{He}^{1, *}$, Jun Wang ${ }^{2}$ and Liang Zhang ${ }^{1}$ \\ ${ }^{1}$ Guizhou Normal University, Guiyang, 550025 \\ ${ }^{2}$ Zhejiang University of Water Resources \& Electric power, Hangzhou, 310018 \\ ${ }^{*}$ Corresponding author
}

\begin{abstract}
The information service industry is regarded as one of the new poles of growth for China's economy with much more effective productivity of factors and it is overall most competitive in the Yangtze River Delta region. In this paper, the quantitative analysis of total factor productivity (TFP) growth and development factors in Yangtze River Delta were calculated and analyzed by DEA-Malmquist index method and Solow residual value method. It was found that from "11 ${ }^{\text {th }}$ Five" to "12 ${ }^{\text {th }}$ Five" period, the fixed capital and labor investment growth was higher, but the TFP growth was insufficient, which means that it was still in the early stages of development, subject to the constraints of resources, the limitations of labor quality and the lack of technological innovation. However, with the capital marginal returns diminishing, labor quality improving and technological innovation booming, the development of information service industry will gradually move towards the top of the industrial chain and value chain with will total factor productivity rapidly improvement.
\end{abstract}

Keywords-Information services; Total factor productivity; DEA-Malmquist; Supply side reform

\section{INTRODUCTION}

The level of information services has become one of the key factors in measuring national modernization and comprehensive national power [1]. It is proposed to accelerate the promotion of high quality and efficient service industry in the " $13^{\text {th }}$ five-year plan". In the economic development and structural adjustment, the information services industry gets more and more attention as an emerging leading industry. It was clearly proposed in the "2006-2020 national information technology development strategy" to "vigorously develop the digital, network as the main features of the modern information services industry."

Yangtze River Delta region is an important intersection of the strategy of "the Belt and Road Initiatives" and one of the three most developed Economic Zone of China, with great economic vitality, high technological innovation, and massive high-quality talents. The output value of information services industry of Yangtze River Delta, as one of the most developed economic zones in China, has increased from 117.55 billion to 18.96 billion at average annual growth rate of $11.86 \%$ in the "1 1 th $^{\text {th }}$ Five Years" period, and from 241.73 billion to 49.06 billion Yuan at average annual growth rate of $20.3 \%$ in the "12 ${ }^{\text {th }}$ Five-Year Plan" period. The factors, rules of TFP variation were analyzed in this paper in order to provide constructive suggestion and advice to policy makers for economy continuous growth in the " $13^{\text {th }}$ Five-Year" period. Literatures were mainly concentrated on aspects of industrial agglomeration, industrial association, and development factors and so on. In angle of industrial agglomeration, Liu Jianzhun put forward the integrated mode of regional integration of information service industry, which may provide lessons for the synergy innovation of industry [2]. Huo Haitao analyzed the influence factors of industrial agglomeration for the information service industry agglomeration[3]. R.M. Hayes et al. calculated the mutual promotion between information services and manufacturing industry of US with input-output relationship[4]. H.J. Engelbrecht et al. proposed that the information services industry has become an important industry in the process of industrial economy to information economy in developed countries and newly industrialized countries[5]. Benjamin B. Mao et al. found that the productivity growth was due to technological progress according to studies on the information industry output value of 12 OECD Nations [6]. Yen-Chun Chou et al. also found that the technological progress was the main driver of productivity growth, with the Malmquist analyses of innovation, efficiency, and scale changes [7].

As a booming research field, little attention was paid to character and path of development, under the supply-side reform however, which has great theory value and practical meaning. The variation of TFP and the contribution of TFP to the economy growth were calculated by the DEA-Malmqu ist index method and the Solow residual parameter method for the information service industry of Yangtze River Delta region, including Zhejiang, Shanghai and Jiangsu in this paper.

\section{EST IMATION METHOD OF TOT AL FACTOR PRODUCTIVITY}

Nonparametric estimation method is most suitable for panel data with production function estimation and the distance function estimation, avoiding function chosen problems at beginning, such as the data envelopment analysis (DEA) and Malmquist exponential method [8].

\section{A DEA -Malmquist Index Method}

The TFP Malmquist index method was firstly applied by Caves et al.[9] to study the productivity changes with the exponential measurement method. The distance function about the input and output of the Malmquist index was used to represent the variation of productivity over time. Given the distance functionD $\mathrm{D}_{\mathrm{i}}^{\mathrm{t}}\left(\mathrm{x}^{\mathrm{t}}, \mathrm{y}^{\mathrm{t}}\right)$ the TFP index based on inputs can be expressed as the following Malmquist index. 


$$
M_{i}^{t}=\frac{D_{i}^{t}\left(x^{t}, y^{t}\right)}{D_{i}^{t}\left(x^{t+1}, y^{t+1}\right)}
$$

It indicates the changes of technical efficiency from period $t$ to $t+1$, according to the technical conditions in period $t$. The Malmquist index was decomposed into technical efficiency changes (effch) and technological changes (techch) by Fare[10]. The technical efficiency change index can be decomposed into pure technical efficiency index (pech) and scale efficiency index (sech). It means that the productivity is improved if the Malmquist index is bigger than 1. If the Malmquist index equals to 1 , it means no changes to the productivity in the two periods. However, if the Malmquist index is less than 1, that is to say, the productivity gets decreased.

$\mathrm{M}_{\mathrm{i}}\left(\mathrm{x}^{\mathrm{t}+1}, \mathrm{y}^{\mathrm{t}+1} ; \mathrm{x}^{\mathrm{t}}, \mathrm{y}^{\mathrm{t}}\right)=\operatorname{pech} * \operatorname{sech} * \operatorname{techch}(2)$

\section{B Data and Parameters}

There is no special statistical organization for the Yangtze River Delta region, so we need to summarize statistical data of different yearbooks of those regions in the Yangtze River Delta. Our main industrial data are adopted and reorganized from official statistical year books, e.g. "China Statistical Yearbook", "Zhejiang Statistical Yearbook", "Jiangsu Statistical Yearbook", and "Shanghai Statistical Yearbook". The sample of the information services industry is the input and output data of the Yangtze River Delta region's from 2004 to 2015.

The output of the information service industry was expressed by the annual revenue of information transmission, computer services and software industry in Shanghai, Zhejiang province and Jiangsu province. As the production price index (PPI) of the information service industry is not available in current statistical system, the added value was regarded directly as a measurement of output, instead of the national production price index with bias. Theoretically, labor input to one industry is the "service flow" provided by labor factors in a certain period, with the amount, quality and labor factors of labor factors to be considered. It will be much smaller than reality if only the amount of labor is counted to calculate contribution of the labor factors to economic growth. But in practice, the number of employees at the end of the year is usually used as labor input because the quality and efficiency of labor factors are unavailable in current statistical system.

The capital investment refers to the amount of capital actually used in the economic system. The capital stock is usually used as a measurement of capital investment for application convenience. The most popular method of capital stock calculation is the perpetual inventory method proposed by Goldsmith [10]. It involves the new added capital, capital depreciation, inflation of prices and other things. In this paper, the improved method of the perpetual inventory method by Zhang Jun et al[11] was adopted to estimate the annual stock of capital, which is shown as follows.

$$
K_{t}=K_{t-1}(1-\delta)+\frac{I_{t}}{P_{t}}
$$

There are four variables in the formula, which are capital stock in base year $\mathrm{K}_{0}$, the depreciation rate $\delta$, the amount of fixed assets investment in t-period It, and the fixed asset investment price index in t-period Pt..It is a hotspot in academicals research to determine the capital stock of base year $\left(\mathrm{K}_{0}\right)$. It will affect the estimation of capital stock in former period according to the value of capital stock of base year. But the impact gets less and less to the capital stock estimation in subsequent period for the mechanism of depreciation. There are several methods to estimate the capital stock in literatures. E.g. in Shan Haojie's [12] way, it was calculated as the ratio of the sum of the investment in the base period to the sum of the average growth rate of investment and the depreciation rate; from Reinsdorf et al.[13]; and it was estimated by the relationship among input-output depreciation and capital stock proposed by $\mathrm{Xu}$ Jie et al.[14]. The method of Reinsdorf et al. [13] was adopted in this paper to estimate the base capital stock $\mathrm{K}_{0}$.

$5 \%$ was adopted in many literatures according to the results of Wang Xiaolu et al[15], for no official depreciation data in statistical system. And $9.6 \%$ was adopted as depreciation rate of the information service industry from the results of Zhang Jun [11].

\section{EMPIRICAL ANALYSIS FOR YANGTZE RIVER DELT A}

There are five types of variations for TFP, which are strong growth with tfpch bigger than 1.2, highly effective growth with tfpch between 1.1 and 1.2, low effective growth with tfpch between 1 and 1.1, low inactive long with tfpch between 0.9 and 1 , and high invalid growth with tfpch between 0.8 and $0.9[16]$. The values of TFP index for the information service industry in the Yangtze River Delta were calculated by the tool of DEAP2.1, shown in Table 1[17]. It is obviously that there were two peaks for the TFP of the information service industry in the period of 2006 to 2015, and an obvious decline in 2008 to 2009 for the global financial cris is, according to and figure 1 . It can be concluded that the technology change in 2012-2013 was the main reason for TFP change.

According to the analysis of technical efficiency and technology progress, the average growth rate of technical efficiency was $-0.55 \%$, while the average growth rate of technological progress was $0.99 \%$. It means that the technological progress is a major factor of TFP increase, and the technical efficiency is somewhat a handicap to TFP progress.

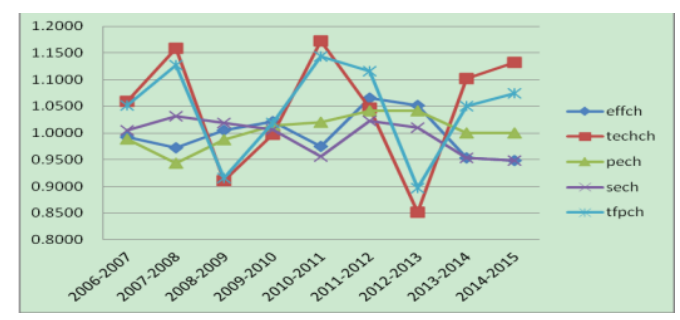

FIGURE I. AVERAGE TFP INDEX (2006 2015)

The total factor productivity of information service industry differs in different regions of the Yangtze River Delta, as shown in Table 2. The average growth rate of Malmquist production index, technical efficiency, and technological progress in Zhejiang Province are respectively $7.8 \%, 1.9 \%$ and $5.7 \%$. It is a relative high level of information service industry 
in the Yangtze River Delta mainly for policies support of modern service industry, wildly application of E-commerce, and prosperous private economy in Zhejiang. The values of those three parameters in Shanghai are 6.3\%, $1.7 \%$ and $4.6 \%$ respectively, as a proof of the promotion role of developed economy, higher informatization level and government support to the development of information service industry. However, Jiangsu gives us another experience with three unsatisfied values, less than $1,-4.1 \%, 2.5 \%$.It indicates that the resources, technology and capital have not optimized allocated in the process of industrialization to informatization and servitization.

According to table 1, the average growth rate of technological progress is greater than the average increase in technical efficiency, which means that great success has been achieved in the Yangtze River Delta, but the technical efficiency still need further progress.

T ABLE 1MALMQUIST INDEX IN THE YANGT ZE RIVER DELT A

\begin{tabular}{|c|c|c|c|c|c|}
\hline area & effch & techch & pech & sech & tfpch \\
\hline zhejiang & 1.019 & 1.057 & 1.011 & 1.008 & 1.078 \\
\hline shanghai & 1.017 & 1.046 & 1.000 & 1.017 & 1.063 \\
\hline jiangsu & 0.959 & 1.025 & 1.000 & 0.959 & 0.983 \\
\hline
\end{tabular}

\section{CONTRIBUTION OF TFP TO THE DEVELOPMENT OF INFORMATION SERVICE INDUSTRY}

The above estimation of TFP shows that there are some differences for different TFP components and different regions of information service industry in the Yangtze River Delta. For further study on contributions of TFP to the development of information service industry, some more in-depth and comprehensive job is needed.

\section{A Measurement of TFP}

Factually, it can only calculate relative variation index by the Malmquist index method, not the real TFP, which could only be used to describe the variation trend of TFP. The production function is usually the direct way to calculate the value of TFP. One popular production function is Cobb-Douglas production function (C-D production function).According to the Solow hypothes is, capital, labor and technological progress are correlation factors to as the total output, given constant returns to scale and substitutability of labor and capital[16].The general form of the Solow production function is expressed as follow.

$$
Y_{t}=A_{t} K_{t}^{\alpha} L_{t}^{\beta}
$$

The total output value in year $t$ is represented by $Y_{t}$, and technical level, capital and labor input are represented by $A_{t}$ 、 $\mathrm{K}_{\mathrm{t}}$ 、 $\mathrm{L}_{\mathrm{t}}$ respectively. $\alpha$ and $\beta$ are the elasticity of capital and labor factor inputs for total output. Equation (4) can be reformed with natural logarithm transformation as follow.

$$
\ln Y_{t}=\ln A_{t}+\alpha \ln K_{t}+\beta \ln L_{t}
$$

It is a linear equation now. With time series of output, capital and labor, the value of $\alpha$ and $\beta$ could be evaluated by equation (5), Therefore, the TFP could be represented by the following equation.

$$
A=y-\alpha k-\beta I
$$

A represents the average growth rate of generalized technological progress, Y represents the average growth rate of output, $\alpha$ is the elasticity coefficient of capital, $\beta$ is the elasticity coefficient of labor. For the precondition of constant returns to scale, if $\alpha$ plus $\beta$ is greater than 1 , standardize is needed with $\alpha_{\mathrm{k}}=\frac{\alpha}{\alpha+\beta}$ and $\beta_{\mathrm{l}}=\frac{\beta}{\alpha+\beta}$.

\section{B Empirical Results} (5).

The regression equation is shown as follows with equation

$$
\begin{gathered}
\ln \mathrm{Y}=-2.43+1.2 \ln \mathrm{K}+0.2 \ln \mathrm{l} \\
\mathrm{R}^{2}=0.989 \mathrm{~F}=98.35 \mathrm{DW}=2.32
\end{gathered}
$$

With a much satisfied value of $\mathrm{R}^{2}$ close to 1 , the fitting effect of the regression equation is much better. The sum of $\alpha$ and $\beta$ is bigger than $1, \alpha+\beta=1.4>1$, regularization is needed. According to standardize rule, the new capital elasticity coefficient $\alpha_{k}$ is 0.875 , and the new labor elasticity coefficient $\beta_{1}$ is 0.143 . So the TFP can be represented by the following equation based on formula (6).

$$
\mathrm{TFP}=\mathrm{y}-0.857 \mathrm{k}-0.1431
$$

With values of output, capital and labor, the growth rate of TFP from 2006 to 2015 and the contribution to revenue growth can be evaluated, as table 2 shows. The average annual growth rate of revenue in 2006 to 2010 period is $11.86 \%$ and it is $20.30 \%$ in 2011 to 2015 period. The growth rate of capital is greater than labor, which could explain that the growth rate of TFP is at a low level except a maximum of $21.73 \%$ in the $2010-2011$ periods.

\section{T ABLE 2 GROWT H OF REVENUE, CAPIT AL, LABOR AND TFP}

\begin{tabular}{|c|c|c|c|c|}
\hline Period & $\begin{array}{c}\text { Growth of } \\
\text { Revenue }\end{array}$ & $\begin{array}{c}\text { Growth of } \\
\text { Capital }\end{array}$ & $\begin{array}{c}\text { Growth of } \\
\text { Labor }\end{array}$ & $\begin{array}{c}\text { Growth of } \\
\text { TFP }\end{array}$ \\
\hline $2006-2007$ & $16.44 \%$ & $8.80 \%$ & $10.51 \%$ & $7.39 \%$ \\
\hline $2007-2008$ & $15.04 \%$ & $9.48 \%$ & $2.50 \%$ & $6.56 \%$ \\
\hline $2008-2009$ & $4.20 \%$ & $11.87 \%$ & $9.69 \%$ & $-7.35 \%$ \\
\hline $2009-2010$ & $14.12 \%$ & $11.62 \%$ & $11.39 \%$ & $2.54 \%$ \\
\hline $2010-2011$ & $30.70 \%$ & $7.91 \%$ & $15.34 \%$ & $21.73 \%$ \\
\hline $2011-2012$ & $19.97 \%$ & $9.05 \%$ & $8.74 \%$ & $10.96 \%$ \\
\hline $2012-2013$ & $20.45 \%$ & $12.33 \%$ & $102.22 \%$ & $-4.74 \%$ \\
\hline $2014-2015$ & $19.15 \%$ & $17.77 \%$ & $0.71 \%$ & $3.82 \%$ \\
\hline
\end{tabular}

Information service industry is a high-tech industry with information technologies, which need more technology and knowledge investment. Low return on capital is finally an inevitable result when its development is relied on capital. As an economic indicator of investment efficiency, Incremental Capital-Output Ratio (ICOR) is used to measure the amount of input required for unit output growth. The higher the ICOR of the economy is, the lower the investment efficiency and production efficiency will be[18]. 


$$
\mathrm{ICOR}=\Delta K / \Delta \mathrm{Y}
$$

As figure 2 shows, the highest point for the ICOR of the information service industry is 2009 , and the lowest is 2011.There is a rising tendency for ICOR from 2011, that is to say, the capital investment efficiency of the information services industry in the Yangtze River Delta will decline year by year or become stable in the future. It becomes more and more difficult to maintain the development of information services relying on capital. Changes in the development mode and path of information service industry are needed for the diminution of capital returns. The rule of decreasing returns to scale tells that only technological innovation and application efficiency may create increasing returns. As a high-tech industry, information service industry develop well at beginning, but once there is not enough innovation or technology progress, returns to scale comes decreasing, which is shown in figure 2 .

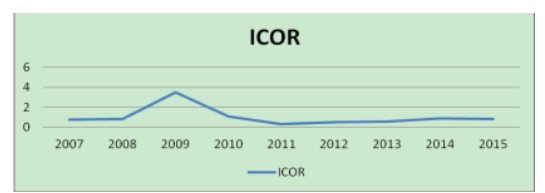

\section{FIGURE II.ICO OF INFORMATION SERVICE INDUST RY IN YANGTZE RIVER DELT A}

Contributions of capital, labor and TFP are listed in table 3. It shows that the contribution of capital to the economic growth of information service industry is relatively stable, while capital becomes more and more stable. In 2006 to 2015 period, the contribution of capital can be regarded as one of the main driving factors to the development of information service industry with a value as high as $88.87 \%$. The average contribution rate of capital is $92.44 \%$ withrapid growth and that of labor is $64.18 \%$ withdecline growth tendency. By comparison among capital, labor and TFP, it shows that at present the information service industry is still in the early stages of development, mainly relying on capital and labor. But the high growth of TFP will be the source of economic development in the future with less and less dependence on capital and labor.

T ABLE III.CONTRIBUTION RATES

\begin{tabular}{|c|c|c|c|}
\hline Period & Capital & Labor & TFP \\
\hline $2006-2007$ & $53.55 \%$ & $63.94 \%$ & $44.97 \%$ \\
\hline $2007-2008$ & $63.02 \%$ & $16.59 \%$ & $43.62 \%$ \\
\hline $2008-2009$ & $282.33 \%$ & $230.52 \%$ & $-174.92 \%$ \\
\hline $2009-2010$ & $82.24 \%$ & $80.64 \%$ & $17.99 \%$ \\
\hline $2010-2011$ & $25.77 \%$ & $49.96 \%$ & $70.77 \%$ \\
\hline $2011-2012$ & $45.32 \%$ & $43.75 \%$ & $54.90 \%$ \\
\hline $2012-2013$ & $60.30 \%$ & $499.91 \%$ & $-23.16 \%$ \\
\hline $2013-2014$ & $94.53 \%$ & $24.35 \%$ & $15.50 \%$ \\
\hline $2014-2015$ & $92.81 \%$ & $3.72 \%$ & $19.93 \%$ \\
\hline
\end{tabular}

\section{CONCLUSIONS AND SUGGESTIONS}

In this paper, the Malmquist index method based on DEA model and the Solow residual method are used to analyze the contribution of TFP to the information service industry in Yangtze River Delta from 2006 to 2015 with following conclusions.

(1) TFP and total TFP index differ in different periods according to different factor input, technical efficiency and technical application.

(2) Information service industries in both Zhejiang and Shanghai develop in a low efficient growth type in TFP, but low inefficient growth type in Jiangsu province. It is suggested that taking good advantage of factors in the whole region, such as economic, technological, human and others to achieve high effective growth in TFP in Yangtze River Delta, relying on technology progress and innovative applications.

(3) More attention should be paid on innovation and technology progress in information service industry to achieve endogenous growth, not only capital and labor.

One essence of supply side structure reform is to gain increasing returns to scale by improving TFP, so as the information service industry in Yangtze River Delta to compete in international markets. TFP is a main index of technology process for industry. Technology progress according to innovation and its application is the core of endogenous growth of economy, which is relying on R\&D. Therefore, the governments should firstly optimize the allocation of resources and increase investment in $R \& D$, including infrastructure, vocational and academic education. Secondly private investment on R\&D should be encouraged with promotion policies. Thirdly, an effective mechanism should be established for intellectual property protection and risk investment.

\section{ACKNOWLEDGEMENT S}

This paper is sponsored by Humanity and Social Science Foundation for Young Scholars of Education Ministry (Grant No. 13YJC630164, 14YJC630109) and Soft Science Research Program of Zhejiang (Grant No. 2018C35053).

\section{REFERENCES}

[1] Zhu Z Y, Li N, Wang J H, Research on the Effect and Spreading Effect of Shanghai Modern Information Service Industry, Shanghai Journal of Economics, 2012,(9), pp.43-54.

[2] Liu J Z, Jiang B, Research on the Integrated Mode of Regional Integration of Modern Information Service Industry, Journal of Modern Information, 2016, 36(12), pp. 19-23.

[3] Huo H T, Zhao X W, Agglomeration \& Influencing Factors of China 's Information Service Industry Journal of Beijing Institute of Technology(Social Sciences Edition), 2017, 19(3), pp. 83-91.

[4] Robert M.Hayes, Timothy Erickson, Added Value as a function of perchance of Information Services., The Information Society, 1981, 1(4), pp.307-338.

[5] HansJurgen Engelbrecht, Are Purchased Information Services Underused in ManufacturingEvidence From Japan, Korea and Taiwan, Applied Economics, 1990.

[6] Benjamin B.M shao, Winston T.Lin, Assessing output performance of information technology service industries: Productivity, innovation and catch-up Original International Journal of Production Economics, 2016, (172), pp. 43-54.

[7] Yen-Chun Chou, Beniamin B.M. Shao, Total factor productivity growth in information technology services industries: A multi-theoretical perspective, Decision Support Systems, 2014, 62(1246), pp. 106-118. 
[8] Yang Q K, Duan X J, Study on the Spatio-Temporal Measure and Inter-provincial Difference of High-tech Industry Development Efficiency Based on DEA-Malmquist Model, Economic Geography, 2014, 34(7), pp.103-110.

[9] Caves D W, Christensen L R, Diewert W E, The economic theory of index numbers and the measurement of input and output, and productivity, Econometrica, 1982, 50(6), pp. 1393-1414.

[10] R. Fare, S. Goldsmith, C.A.K Lovell, Productivity Change in Swedish Pharmacies $1980 \sim$ 1989:A Nonparametric Malmquist Approach, Journal of Productivity Analysis, 1992,(3), pp. 85-101.

[11] Zhang J, Wu G Y, Zhang J P, China 's inter - provincial material capital stock estimates: 1952 -2000, Economic Research Journal, 2004, (10), pp. 35-44.

[12 Shan H J, Revaluation of China 's Capital Stock K: 1952 - 2006, The Journal of Quantitative \& Technical Economics, 2008, (10), pp. 17-31.

[13]Marshall, Reinsdorf, Mariam Cover, Measurement of Capital Stocks, Consumption of Fixed Capital, and Capital Services, Report on a Presentation to the Central American Ad Hoc Group onNational Accounts, 2005.

[14] Xu J, Duan W C, Yang J L, Revaluation of China 's Capital Stock, Statistical Research, 2010, 27(12), pp. 72-77.

[15] Wang X L, Fan G, Sustainability of China 's Economic Growth Review and Prospect of Cross - century, Economic science press, 2000.

[16] Zhao J H, Milike M, Xu Y M, Dynamic Analysis on the Efficiency of FDI in China's Regions - Malmquist Index Method Based on DEA Model, Management Review, 2013， 25(4), pp. 32-37.

[17] Coelli T J, A guide to DEAP version 2.1: A Data Envelopment Analysis Program, CEPAW orking Paper, 1996.

[18] Fan F Z, Li Q, International Technology Spillovers and the Efficiency of China's Capital Allocation - A Comparison between FDI Channel and Import Trade Channels, Social science front, 2017, (3), pp. 42-48. 